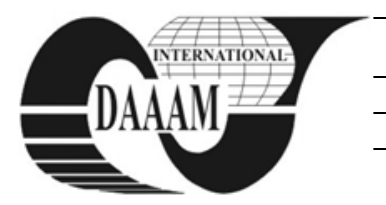

Annals of DAAAM for 2011 \& Proceedings of the 22nd International DAAAM Symposium, Volume 22, No. 1, ISSN 1726-9679 ISBN 978-3-901509-83-4, Editor B. Katalinic, Published by DAAAM International, Vienna, Austria, EU, 2011 Make Harmony between Technology and Nature, and Your Mind will Fly Free as a Bird Annals \& Proceedings of DAAAM International 2011

\title{
THE IDENTIFICATION PROCEDURE FOR KEY MANAGERIAL COMPETENCIES IN INDUSTRIAL ENTERPRISES
}

\author{
BANASOVA, L[ucia]; CAGANOVA, D[agmar]; CAMBAL, M[ilos] \& SUJANOVA, J[ana]
}

\begin{abstract}
The article puts the emphasis on the importance of the competency approach to human resource management application in industrial enterprises. Nowadays it is regarded as the most effective way to achieve the long-term sustainable enterprise performance. To apply the competency approach in industrial enterprises, it is necessary to relatively precisely determine and define the key competencies of the employees, particularly of employees in managerial positions.

The article develops a proposed identification procedure for key managerial competencies in the context of industrial enterprises.
\end{abstract}

Key words: competency, manager, enterprise, performance, competitiveness

\section{INTRODUCTION}

Human resources are the most important and at the same time the most complicated resources in each organisation. This is due to the fact that through their efforts all other organisational resources are "activated". The complications of human resources are due largely to the fact that emotional issues cause unpredictable behaviour in organisational management. At present industrial enterprises are increasingly realising the value of their employees, particularly employees working in managerial positions, because the managers primarily influence in a decisive way the level of their competitiveness. For this reason enterprises should know what knowledge, skills, and abilities their managers have for reaching long term sustainable development (Witkowski, 2009). In the professional literature it is possible to find characteristics for a successful manager, however these are often too general to be applied in a manner to maintain success in the particular conditions of the specific enterprise.

\section{THE COMPETENCY APPROACH TO HUMAN RESOURCE MANAGEMENT}

Probably the most effective method of human resource management in industrial enterprises is the utilisation of the competency approach. The competency approach has significantly influenced all areas of human resource management and has offered new insight into the possibility of improving enterprise performance (Hoghová, 2009). The basic prerequisite for adopting the competency approach is the identification and precise definition of key competencies for enterprise managers.

For research purposes in the context of industrial enterprises in the Slovak Republic in 2010- 2011, in order to create an identification procedure for key managerial competencies, we have used the following definition of the particular term: a combination of knowledge (a complex of accumulated cognitions), skills (specific abilities to carry out specific activities), attitudes (steady ways of behaviour which are created on the basis of experience) as well as personal characteristics (a complex of intelligence, emotional and physical properties) used by the employee in his/her work and enabling him/her to achieve excellent (above standard) performance. Such performance exceeds average performance of the defined group of managers at least by the value of one standard deviation.

\section{THE IDENTIFICATION PROCEDURE FOR KEY MANAGERIAL COMPETENCIES}

The focus was placed primarily on creating a methodological procedure of KMC identification. These competencies secure the excellent performance of a manager in particular conditions of a specific enterprise. The main goal was not to create a strict (unified) procedure of identification, but to provide a basic methodological framework whereby all the suggested steps of identification are detailed. These can be adjusted by the enterprise to match its own specific conditions.

The KMC identification process in the particular conditions of industrial enterprises will be influenced by both the enterprise culture and the intention of utilising the identified competencies (Cagáňová et al., 2010). The competency model will be developed by utilising the managerial key competency outputs identified. It will consist of those competencies that are necessary to reach the excellent performance of a manager at a particular position. The suggested procedure consists of 10 steps presented in Fig.1.

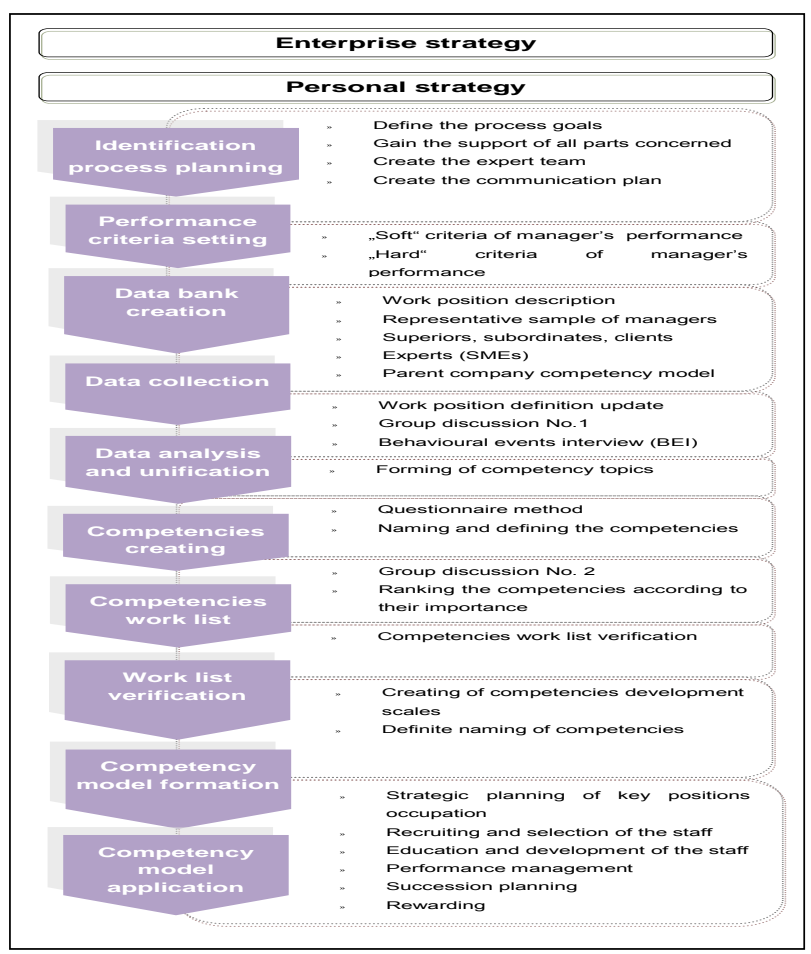

Fig.1. The identification procedure for key managerial competencies 
The KMC process should develop from the overall strategy and the personal strategy of the enterprise, so that the competencies can be identified and deliver the enterprise strategy, as well as reaching the long term goals of the enterprise.

The first step of this process is the phase of planning the KMC identification process. This phase is a critical aspect because it leads to the definition of all determining questions of identification and it presents a base for the successful application of identified KMC's into practice. Within this step it is necessary to define the goals of identification, gain the support on the part of management, particularly those who will be involved in the identification. Moreover, it is necessary to create a team for the KMC identification process and to set the communication plan.

The next step of KMC identification is to set the performance criteria that would be instrumental to define the effective performance measurement for managerial positions. Within this step, it is necessary to set the criteria of performance for managerial positions that will include reliable data reflecting the enterprise's performance management, socalled hard criteria (sale, profit, productivity, if they exist for the given work place), but also for so-called soft criteria (criteria of the manager's behaviour-willingness to assume risk, cooperation, flexibility, relationships with the colleague).

In the third phase of this procedure, it is necessary to create a kind of data bank that will be instrumental to gain the information necessary to identify KMC's in the particular enterprise. The data bank may contain, e.g., the working position description, a representative sample of managers, relevant employees, clients, and experts (SMEs - subject matter expert), a parent company competency model and so on. Collecting and utilising the individual data sources will be dependent on the defined goals of KMC identification and on the managerial positions for which the competencies will be identified by the enterprise. Data source options will be influenced by financial and time sources selected for the whole process.

While identifying the KMC, there should be at least two data collection methods adopted. If the data collected by the first method is consistent with the data collected by the second method, there is greater credibility and certainty that the KMC will be identified accurately. According to experts in the field of the competency approach, the most suitable methods to reveal managerial competencies are: a structural interview (BEI, RGI), panel and questionnaire methods (Kubeš et al., 2004), (Cripe\& Mansfield, 2002).

In the fifth phase, the data gained by means of the data collection method will be analysed so the behaviours could be identified, particularly those that differentiate excellent managers from average ones. Expert team analysts will review the data and identify the behaviours that are either present or absent in excellent managers when compared with those managers who are average. The results of this step will present grouped related behaviour occurrences that will form the basis for outlining the KMC.

In the sixth phase, the expert team will rework these grouped behaviours and create definitions of competencies so that they can describe as exactly as possible the behaviour which each given competency characterises. In the next phase, the list of competencies important for managerial positions will be formulated using the competency glossary, with the help of discussion group No.2. The goal of this discussion group will be the creation of a list of competencies that differentiates the excellent managers from the average ones and ranks them according to importance concerning the excellent performance required for a given position.

The KMC list proposal should be verified by experts from the given field. The authors recommend the use of a questionnaire for this verification. Output from this step will be presented as a list of KMC's ranked according to their importance to reach performance excellence and will then form the base for creating the competency model .

For each managerial competency, there should be examples of behaviour created on different levels. Consequently each competency will be clearly defined and named.

The value of the identified KMC consists in their application to the personnel processes of a particular industrial enterprise. This value is maximized if the competencies are implemented within all personnel processes. For this reason, the last step of KMC identification is presented by application of the created competency model into personnel processes. This model describes the way to implement the competency model into the personnel processes on the basis of the stated methodology. Personnel processes are identified as the following: strategic planning of the key position occupations, recruiting and selection of the staff, education and development of the staff, performance management, succession planning, and employees' rewarding.

To ensure the created competency model is adopted as a real tool of industrial enterprise performance increase, the key competency list should be updated according to the enterprise strategy and the other key factors of changes. In conclusion of the whole KMC identification process, the expert team needs to set the schedule of the competency model examination. In the instance where no distinctive changes in the given enterprise are required, group discussions or questionnaires may be used to update. If the managerial positions change markedly, or expressive changes come into being within the enterprise, it is necessary to perform a new process of KMC identification.

\section{CONCLUSION}

The main goal of creating the KMC identification procedure in the context of industrial enterprises operating within the Slovak Republic was to set the conditions for long term achievement of the enterprise performance required. Demand for creating such a procedure also came from the findings that industrial enterprises in Slovakia do not have enough information on the competency approach and its contribution. At the same time, nearly half of the enterprises participating in the above mentioned research displayed interest in KMC identification and the creating of competency models. The suggested recommendations form a methodological framework to identify KMC that could be adjusted by every enterprise according to its own specific conditions. Successful application of this procedure can help the stated subjects to succeed in the competitive struggle and, at the same time, reach long term sustainable development through their own employees.

\section{REFERENCES}

Cagáňová, D.; Čambál, M. \&WeidlichováLuptáková, S. (2010). Intercultural Management - Trend of Contemporary Globalized World.Electronics and Electrical Engineering, No. 6 (2010). pp. 51-54, ISSN 1392-1215

Cripe, E. \& Mansfield, R. (2002).The value-added emploee: 31 competencies to make yourself irresistible to any company. Butterworth Heinemann, ISBN: 0-756-7451-22002, Massachusetts, $198 \mathrm{p}$.

Hoghová, K. (2009). Comprehensive analysis of Organizational Culture - the basic condition of its forming.Proceedings of the CO-MAT-TECH 2009, Industrial Engeneering, Management and Quality for 21st century, pp. 119-124, ISBN 978-80-8096-100-8, October 2009, Alumni, Trnava

Kubeš, M.;Spillerová, D.\&Kurnický, R. (2004).Manažérskekompetence Grada Publishing, ISBN: 80-247-0698-9, Praha, 184 p.

Witkowski, K. (2009). The innovations for sustainable development. Proceedings of the CO-MAT-TECH 200ISBN 978-80-8096-100-8, October 2009, AlumniPress, Trnava 